\title{
Randomised clinical trial of rice germ supplementation on nutritional status and performance in trained swimmers: A pilot study
}

\author{
Mariangela Rondanelli ${ }^{1,2}$, Simone Perna ${ }^{3}$, Gabriella Peroni ${ }^{4}$, Milena A. Faliva ${ }^{4}$, \\ Mara Nichetti ${ }^{4}$, Giancarlo Iannello ${ }^{5}$, Vittoria Infantino ${ }^{2^{*}}$, Clara Gasparri ${ }^{4}$, \\ Daniele Spadaccini ${ }^{4}$ \& Davide Guido ${ }^{6}$
}

${ }^{1}$ IRCCS Mondino Foundation, Pavia; ${ }^{2}$ Department of Public Health, Experimental and Forensic Medicine, Unit of Human and Clinical Nutrition, University of Pavia, Pavia, 27100, Italy; ${ }^{3}$ Department of Biology, College of Science, University of Bahrain, Sakhir Campus P.O. Box 32038 Kingdom of Bahrain; ${ }^{4}$ Endocrinology and Nutrition Unit, Azienda di Servizi alla Persona "Istituto Santa Margherita", University of Pavia, Pavia, 27100, Italy; ${ }^{5}$ General Management, Azienda di Servizi alla Persona "Istituto Santa Margherita", Pavia, 27100 Italy; ${ }^{6}$ Neurology, Public Health and Disability Unit, Scientific Directorate, IRCCS Foundation Neurological Institute Carlo Besta, Milan, 20133, Italy

\begin{abstract}
Introduction: Rice germ (RG) could be a safe and effective dietary supplement for swimmers. Methods: This randomised, parallel, placebo controlled pilot study investigated the effect of a five-week RG supplementation (25 grams/two times/day) in moderately trained swimmers on 50-m and 200-m front crawl at maximal speed, as primary outcome, and body composition, muscle function, post-concussion assessment, cognitive testing (ImPACT) and lactic acid levels, as secondary outcomes. Twenty seven moderately trained swimmers (7 women and 20 men) participated in the study. Results: For primary outcome on 200-m front crawl at maximal speed, a significant average decrease of 2.98 seconds $(p=0.022)$ was detected in RG group, but it was not significant compared to placebo. On 50-m front crawl at maximal speed, no statistically significant intra- or inter-group differences were detected. Regarding secondary outcomes, no difference was demonstrated between preperformance and post-performance lactic acid levels. Comparing the treatment with placebo across follow-up, mean mid-arm muscle circumference (MAC) increased weekly and significantly by $0.23 \mathrm{~cm}(p=0.026)$, as well as $0.36 \%$ for gynoid fat $(p=0.005)$. In addition, a decrease of $0.13 \mathrm{~kg}$ in fat-free mass $(p=0.067)$ was also detected. No statistically significant intra- or inter-group differences were detected for secondary outcomes. Conclusion: This pilot study provided early evidence that RG supplementation may positively affect nutritional status and partially, the performance of moderately trained swimmers. Further research is needed to clarify the mechanisms of action, the optimal timing of supplementation, as well as the most effective dose.
\end{abstract}

Keywords: Rice germ, swimmers, nutritional supplement, lactic acid, fat-free mass

*Corresponding author: Dr. Vittoria Infantino

Department of Public Health, Experimental and Forensic Medicine, Unit of Human and Clinical Nutrition c/o Azienda di Servizi alla Persona "Istituto Santa Margherita", University of Pavia, Pavia, 27100, Italy Tel: +39-0382-381706; E-mail: viriainfantino@hotmail.it doi: https://doi.org/10.31246/mjn-2019-0071 


\section{INTRODUCTION}

In order to enhance the effects of training and improve performance, athletes often turn to nutritional supplements (Knapik et al., 2016). According to the American College of Sports Medicine (ACSM), adequate selection of nutrients and supplements, and adjusting intake according to the exercise performed, are necessary for optimal performance in athletes (Rodriguez et al., 2009). The most recent consensus from the International Society for Sports Nutrition (ISSN), American Dietetic Association (ADA) and ACSM on sports nutrition have been reviewed by Potgieter, stating that a single guideline is not sufficient to elaborate an individualised and focused nutritional management for athletes. Moreover, apart from the above mentioned guidelines, sport-specific nutritional strategies, including quantity, structure and timing of food (or supplement) intake should also be followed in order to maximise sports performance and recovery (Potgieter, 2013). The importance of dietary supplementation is of particular interest in swimming, where athletes usually undertake a training approach characterised by a high volume of training during aerobic development and high intensity training during the competition phase, coupled with strength training (Stellingwerff, Maughan \& Burke, 2011).

The size and market value of the sports supplement industry is continuing to grow, with health, safety and contamination concerns (Prosser et al., 2009) becoming more pressing. Therefore, it is important to identify dietary supplements that are safe and effective in supporting swimmers. Rice germ (RG) could be a safe and effective dietary supplement for swimmers. In the last few years, scientific research is trying to use rice waste products in the pharmaceutical and nutraceutical fields, considering the potential value of nutrients they contain (Perretti et al., 2003). A recent study (Rondanelli et al., 2019) demonstrated that RG has a high protein content $(18 \mathrm{~g}$ per $100 \mathrm{~g}$ of edible product) with considerable amounts of essential amino acids (mainly lysine, histidine and valine, respectively), fatty acids (mainly monounsaturated and polyunsaturated fattyacidsat $5.65 \mathrm{~g} / 100 \mathrm{~g}$ and $7.65 \mathrm{~g} / 100 \mathrm{~g}$, respectively), and fibre (7g per $100 \mathrm{~g})$. Regarding water-soluble vitamins, RG has high amounts of thiamine (vitamin B1) and pyridoxine (vitamin B6), while vitamin $\mathrm{E}$ is the main fat-soluble vitamin present. Iron $[77 \%$ of Recommended Dietary Allowance (RDA)] and magnesium (108\% of RDA) are the two main minerals found in RG. The nutritional composition of RG is shown in Table 1, based on an evaluation done by Chelab (Treviso, Italy). Given its great nutritional value, it will be of interest for future studies to explore ways to incorporate RG into dietary supplements aimed at increasing nutritional intake for a specific population, such as athletes. In fact, all these nutrients contribute synergistically to muscle activity and play important roles in maintaining the health of athletes (Manore, Meyer \& Thompson, 2009). Currently, despite these characteristics, no study has evaluated the potential beneficial effects of RG supplementation on athletes.

We chose swimmers as the athletes for this study because an analysis of the mechanics and energetics of swimming revealed that different factors play key roles in the success of competitive swimming events (Toussaint $\&$ Hollander, 1994). The reasons beyond the participation of master athletes in competitions and/or in regular exercise are the enjoyment and its health benefits (Tantrum \& Hodge, 1993), as well as the will to enhance their performance (Maharam et al., 1999). With an increase 
Table 1. Nutritional composition of RG

\begin{tabular}{|c|c|}
\hline Variable & Rice Germ \\
\hline Humidity (g/100g) & 10.5 \\
\hline Protein (g/100g) & 18.2 \\
\hline Fats (g/100g) & 17.5 \\
\hline Dietary fibres (g/100g) & 7.0 \\
\hline Ashes (g/100g) & 5.7 \\
\hline Carbohydrates (g/100g) & 41.2 \\
\hline Energy value (kcal/100g) & 409 \\
\hline Energy value (kJ/100g) & 1711 \\
\hline Starch (g/100g) & 25.5 \\
\hline Vitamin B1 (mg/100g) & 5.8 \\
\hline Vitamin B6 (mg/100g) & 0.5 \\
\hline Vitamin E (mg/100g) & 31.9 \\
\hline Cadmium $(\mathrm{mg} / \mathrm{kg})$ & 0.02 \\
\hline Iron $(\mathrm{mg} / 100 \mathrm{~g})$ & 6.2 \\
\hline Magnesium (mg/100g) & 347.0 \\
\hline Lead(mg/100g) & n.r. \\
\hline Sodium (mg/kg) & 1.9 \\
\hline Aspartic acid (mg/100g) & 95.8 \\
\hline Asparagine (mg/100g) & 74.1 \\
\hline Glutamic acid (mg/100g) & 130.3 \\
\hline Alanine (mg/100g) & 41.5 \\
\hline Arginine (mg/100g) & 115.4 \\
\hline $\begin{array}{l}\text { Cystine (mg/100g) } \\
+ \text { Methionine (mg/100g) }\end{array}$ & $<\mathrm{LoQ}+4.6$ \\
\hline Proline (mg/ 100g) & 21.0 \\
\hline $\begin{array}{l}\text { Phenylalanine }(\mathrm{mg} / 100 \mathrm{~g}) \\
+ \text { Tyrosine }(\mathrm{mg} / 100 \mathrm{~g})\end{array}$ & $3.3+12.2$ \\
\hline Glycine (mg/100g) & 13.9 \\
\hline Glutamine (mg/100g) & 5.3 \\
\hline Isoleucine (mg/100g) & 6.4 \\
\hline Histidine (mg/100g) & 12.7 \\
\hline Leucine (mg/100g) & 8.5 \\
\hline Lysine (mg/100g) & 161.2 \\
\hline Ornithine (mg/100g) & $<$ LoQ \\
\hline Serine (mg/100g) & 20.7 \\
\hline Treonin (mg/100g) & 10.3 \\
\hline Valine (mg/100g) & 18.3 \\
\hline Gamma-aminobutyric acid (mg/100g) & 35.4 \\
\hline IUPAC: 4-aminobutanoic acid & \\
\hline Alpha-aminobutyric acid (mg/100g) & $<$ LoQ \\
\hline IUPAC: 2-Aminobutanoic acid & \\
\hline Saturated fatty acids (g/100g) & 4.15 \\
\hline Monounsaturated fatty acids (g/100g) & 5.65 \\
\hline Polyunsaturated fatty acids (g/100g) & 7.65 \\
\hline
\end{tabular}

n.r. = not reported; LoQ $=$ Limit of Quantification 
in the ageing population and a current trend towards increasing physical activity in adulthood, it is important to understand the relationship between age and physical performance, and to identify the factors affecting it. Therefore, considering the nutritional composition of $R G$, it would be reasonable to expect that the nutritional status of swimmers and their swimming performance could be improved following $\mathrm{RG}$ supplementation.

Most papers evaluating the effectiveness of a dietary supplement in swimmers only considered its acute administration before competition and does not evaluate the efficacy of a chronic supplementation on the state of nutrition. Acute taurine supplementation at 120 minutes before performing a maximal effort did not improve swimmers' performance, but it increased glycerol plasma levels and reduced both the $\Delta\left[\mathrm{La}^{-}\right]$and lactic anaerobic system contribution (De Carvalho et al., 2018). Acute supplementation of sodium citrate prior to a 200-m swimming performance led to a modest time improvement and higher blood lactate concentrations in only half of the swimmers, while chronic sodium citrate supplementation did not provide any ergogenic effect in a group of adolescent swimmers (Russell et al., 2014). Gao et al. (1988) and Siegler et al. $(2010,2012)$ have demonstrated that swimmers ingesting $0.3 \mathrm{~g} \cdot \mathrm{kg}^{-1}$ body mass of sodium bicarbonate (SB) one hour before performance enhanced their blood buffering potential and this positively influenced their interval swim performance. Lindh et al. (2008) have also shown that $\mathrm{SB}$ supplementation $\left(0.3 \mathrm{~g} \cdot \mathrm{kg}^{-1}\right.$ body mass) can improve a single 200-m freestyle performance time in elite male competitors, most likely by increasing the extra-cellular buffering capacity. SB supplementation prior to performing maximal sprint swimming with repetitions under $60 \mathrm{~s}$ improved performance. However, cosupplementation of SB with beta-alanine at 60 minutes before performance did not confer any added benefits on maximal swim performance (Mero et al., 2013). Nitrate supplementation before performance increased nitric oxide bioavailability, but did not benefit short-distance swimming performance (Lowings et al., 2017).

So, our study, differently from all previous literatures on this topic, wanted to consider the effectiveness of chronic supplementation, not acute supplementation, on both the performance and state of nutrition among swimmers. We have chosen five weeks because a previous study has shown that an average of a two-week period on amino acid dietary supplementation did not induce any changes in nutritional status and performance in swimmers (Tang, 2006), while a recent systematic review demonstrated that branchedchain amino acids supplementation for a long period of time (>10 days) was an efficient nutritional strategy (Fouré \& Bendahan, 2017). Given this background, the purpose of this investigation was to ascertain whether performance and nutritional status in swimmers could be improved by a fiveweek RG supplementation. Regarding primary outcome, performance was evaluated by a $50-\mathrm{m}$ and $200-\mathrm{m}$ front crawl at maximal speed in order to assess both the anaerobic and aerobic energy contribution to swimming performance (Toussaint \& Hollander, 1994).

\section{MATERIALS AND METHODS}

\section{Study design and randomisation}

This pilot study was parallel and placebo controlled, and sample size was not determined a priori because the subjects were $>12$ per arm as suggested by Julious 
(2005). Subjects who met the inclusion criteria and who signed the informed consent to the study were assigned consecutively with an ascending number of randomisation, starting with number 1. The number was indicated on a label that identified the treatment and was written on the Case Report Form (CRF). Subjects were randomised to one of the two treatments (refined RG supplement or placebo) according to a randomisation list generated by the computer and according to a pattern that ensured a balance in treatment assignment (according to a 1:1 ratio).

\section{Subjects}

The inclusion criteria of swimmers were: 1. Moderate fitness level, judged on the basis of maximum oxygen uptake $\left(\mathrm{VO}_{2 \max }\right)$ evaluated by means of a standard incremental exercise test on a cycle-ergometer; 2. Regularly involved in regional and national competitions, and who trained an average of $6.5 \pm 0.8 \mathrm{~h}$ per week; 3. Training frequency of 3-4 times/week, with 3.000-5.000 m distance covered each time in a 25-metre indoor swimming pool [Federazione Italiana Nuoto (FIN) swimming pool of Pavia, Pavia, Italy]; 4. In the middle phase of the training season and have trained for $>6$ months. Swimmers with any history of cardiac or respiratory diseases and/ or taking any medications, shown any abnormalities on physical examination or on resting electrocardiogram at the time of the study were excluded. Written informed consent was obtained from all of the participants after they were informed about the methods and aims of the study.

\section{Training schedule}

Athletes trained three or four times/ week. Timing of training was the same for every subject, starting at 9:15 pm and ending at 11:00 pm.

\section{Primary outcome}

Performance measurements

Before and after two weeks and five weeks, swimmers swam in a 25-metre indoor swimming pool, under the same water condition (water temperature of $27^{\circ} \mathrm{C}$ ) to assess a $50-\mathrm{m}$ and $200-\mathrm{m}$ front crawl at maximal speed and the time of performance.

\section{Secondary outcomes}

Anthropometric measurements

All measurements were assessed in the morning between 9:00 am and 10:00 am. Body weight was measured using standardised techniques on a precision scale to the nearest $0.1 \mathrm{~kg}$ with participants wearing light clothing and without shoes. Waist measurements were taken at the midpoint between the lowest rib and the top of the hip bone (iliac crest), with the use of a standardised technique (Frisancho, 1984).

Anthropometric measurements were taken at baseline and after five weeks in both groups. Body weight and height were measured, and Body Mass Index (BMI) was calculated $\left(\mathrm{kg} / \mathrm{m}^{2}\right)$. Skinfold thicknesses (biceps, triceps, suprailiac, subscapular) were measured twice using a Harpenden skinfold caliper at fiveminute intervals at each site, following standardised techniques (Frisancho, 1984). Sagittal abdominal diameter was assessed at the $\mathrm{L}_{4-5}$ level in the supine position and waist girth was also measured. The mid arm circumference (MAC) was taken following standard procedures described by Lohman and colleagues (Lohman et al., 1991). Anthropometric variables were measured by a single investigator.

\section{Body composition evaluation}

Body composition (BC) was assessed using a dual-energy X-ray absorptiometry (DXA) scan (Lunar Prodigy, Madison, 
WI) in all subjects before treatment and again after five weeks intervention period. Evaluation of fat mass (FM), fatfree mass (FFM) were obtained by whole body scan.

\section{Bioimpedance vector analysis (BIVA)}

Whole body impedance measurements were made using standard protocols (Piccoli et al., 1995). A $50 \mathrm{kHz}$, tetra-polar, phase-sensitive BIVA (BIA-101; AKERNSrl, Florence, Italy) which introduced a sinusoidal, alternating current of $400 \mu \mathrm{A}$ RMS was used to measure Resistance $(\mathrm{R})$, Reactance (Xc) and Phase Angle (PA). Measurement errors of the system, determined with a precision resistor and capacitor, were $<1 \%$ for $\mathrm{R}$ and $<2 \%$ for capacitance. The amount of FFM was estimated with a prediction equation for BIVA in adults aged 20-94 years (Kyle et al., 2001). Previous studies that we have performed evidenced that this equation was accurate in our sample (Camina Martín et al., 2013). Fat mass and fat-free mass indices (FMI and FFMI, respectively) were calculated as FMI $(\mathrm{kg} /$ $\left.\mathrm{m}^{2}\right)=\mathrm{FM} / \mathrm{H}^{2}$, and FFMI $\left(\mathrm{kg} / \mathrm{m}^{2}\right)=\mathrm{FFM} /$ $\mathrm{H}^{2}$. These indices were used to compare the $\mathrm{BC}$ data obtained in this study with the reference $\mathrm{BC}$ data for Caucasians (Schutz, Kyle \& Pichard, 2002).

In this study, the reference bivariate tolerance ellipses (50, 75 and 95\% of the distribution of the values in general population) for the adult and elderly men (Piccoli et al., 1995) were used for the qualitative and semi-quantitative assessments of BC and hydration status in each individual subject. The 95\% confidence ellipses for mean vectors of the supplementation group and the placebo group were drawn to compare between these groups.

\section{Muscle function assessment}

The JAMAR Hand Dynamometer (Jamar 5030J1; Sammons Preston Rolyan; accuracy $0.6 \mathrm{~N}$ ) was used to assess muscle function with the use of a standardised procedure (Spijkerman et al., 1991).

\section{Post-concussion assessment and cognitive testing}

Every day, post-concussion assessment and cognitive testing (ImPACT) were compiled (Spijkerman et al., 1991) by swimmers. The ImPACT instrument is a computer-based programme used to assess neurocognitive functions and concussion symptoms. It consists of six tests that evaluate attention, working memory, and processing speed, yielding composite scores on the areas of verbal memory, visual memory, motor processing speed, reaction time, and impulse control (Iverson, Lovell \& Collins, 2003).

\section{Blood lactate evaluation}

Capillary blood samples were collected from the fingertip before and after each swim (at the $1^{\text {st }}$ minute of recovery) to assess the higher value of blood lactate concentration (AccutrendLactate ${ }^{\circledR}$ Roche, Germany).

\section{Dietary supplement}

The intervention group was given $R G$ which consisted of an isocaloric wheat germ-based supplement, while the control group was given a placebo that consisted of an isocaloric amount of fibre with the same flavour and appearance as the intervention product. The RG and the placebo were supplied in vacuum jars weighting at $130 \mathrm{~g}$. These jars, once opened, were stored in the refrigerator $\left(-3-4^{\circ} \mathrm{C}\right)$. Small containers were provided to act as dosers and served to determine the correct dose to be taken (25g, twice a day). The rice germ or placebo were continually taken every day, twice a day $(25 \mathrm{~g}$ in the morning with breakfast and $25 \mathrm{~g}$ in the afternoon as snacks) for five weeks. To optimise compliance, instructions were reinforced weekly by 
phone, by the same research dietitian. The RG was supplied by the company "Acquerello" (Tenuta Colombara, Livorno Ferraris, Vercelli, Italy).

\section{Dietary schedule and intake of energy and macronutrients}

Athletes ate five meals daily: breakfast between 7:00 and 8:00 am, a snack between 10:00 and $10.30 \mathrm{am}$, lunch between 12:00 noon and 2:00 pm, a snack between 4:00 and 4:30 pm, and dinner between 7:00 and 8:00 pm. Individual diet plans were drawn up for each subject by the research dietitian. The energy content and macronutrient composition of the diets adhered to the nutritional recommendations of the position statement for nutrition and athletic performance by ACSM, ADA and Dietitians of Canada (2000). Individual diet plans and dietary records were analysed using a food-nutrient database (Rational Diet, Milan, Italy). Adherence to the diet was checked weekly by a senior dietitian using a food diary.

\section{Adverse events}

Unwanted adverse events, such as headache, nausea, vomiting, dizziness, etc. were expressed as presence/absence or times in which symptoms appeared in the follow-up period, and they were evaluated as tolerability to treatment.

\section{Informed consent and ethical statement}

The investigations were carried out following the rules of the Declaration of Helsinki 1975, revised in 2013. This research was approved by the institutional review board at the University of Pavia and was conducted after approval from the Ethics Committee. The participants included in the study signed a consent form that allowed their personal data to be used in the research. The study was registered on ClinicalTrials.gov PRS: NCT03918785.

\section{Statistical analysis}

Descriptive statistics of the sample were performed using mean \pm standard deviation $(S D)$ values and frequencies. Attrition was handled through complete cases analysis as indicated by the European Medicine Agency Guidelines for exploratory studies (European Medicines Agency, 2010). Associations between treatment $(1=$ refined $R G, 0=$ placebo) and dichotomous variables were analysed with odds ratio (OR) and Fisher's tests, while associations with continuous or counting variables were analysed with mean difference (MD) and paired $t$-test or Wilcoxon signed rank test (if normality assumption was rejected). We applied Linear Mixed Models (LMM) for repeated measures (Fitzmaurice, Laird \& Ware, 2011) to assess athletic performances (i.e. 50-m front crawl times, and lactic acid levels pre- and post-performances) and $\mathrm{BC}$ markers (except height) between two treatments, at baseline and after five weeks (for BIVA markers after two weeks too), as secondary outcomes. We considered the sample $(n=27, \times 2=54$ or $\times 3=81$ obs., but only 27 independents) during five weeks follow-up in which, for each swimmer, the outcomes were measured. LMMs were fitted outcomes using the subjects as random effect. Treatment group, time of assessment (in weeks) and their interactions, were included as explanatory variables. Interaction terms were included into the models as "focus" predictors to evaluate the treatment effects $(\Delta)$, interpreted as mean differences by treatments (RGplacebo), by week. In addition, to get a best fitting model, variables concerned with the adverse events during followup, which resulted to be associated with treatment, were included in the models as potential confounders.

We carried out $z$-tests to evaluate statistical significance on model parameters and a $p$-value $<0.05$ was considered as significant. Analysis was 
performed with R 2.15.3 (Team, 2013) using its nlme (Pinheiro et al., 2007), Rcmdr (Fox, 2005) and lattice (Sarkar, 2008) packages.

\section{RESULTS}

\section{Population}

Twenty seven moderately trained swimmers were recruited to take part in this investigation. The level of their fitness was judged as moderate based on the basis of their maximum oxygen uptake $\left(\mathrm{VO}_{2 \max }\right)$, evaluated by means of a standard incremental exercise test on a cycle-ergometer. Their mean $\pm S D$ of age, body weight, and height were $34.7 \pm 7.5$ years, $69.4 \pm 6.1 \mathrm{~kg}$, and $173.6 \pm 4.3 \mathrm{~cm}$ respectively, while $\mathrm{VO}_{2 \max }$ was $42.7 \pm 2.6$ $\mathrm{mL} \cdot \mathrm{kg} \cdot \mathrm{min}^{-1}$.

\section{Baseline data}

In Figure 1, the flow diagram of the trial is reported. The statistical analysis of the baseline descriptive data showed that the randomisation had been correctly operated and that the refined RG supplementation and placebo groups, except for 50-m free-style times, were homogenous (Tables 2 and 3).

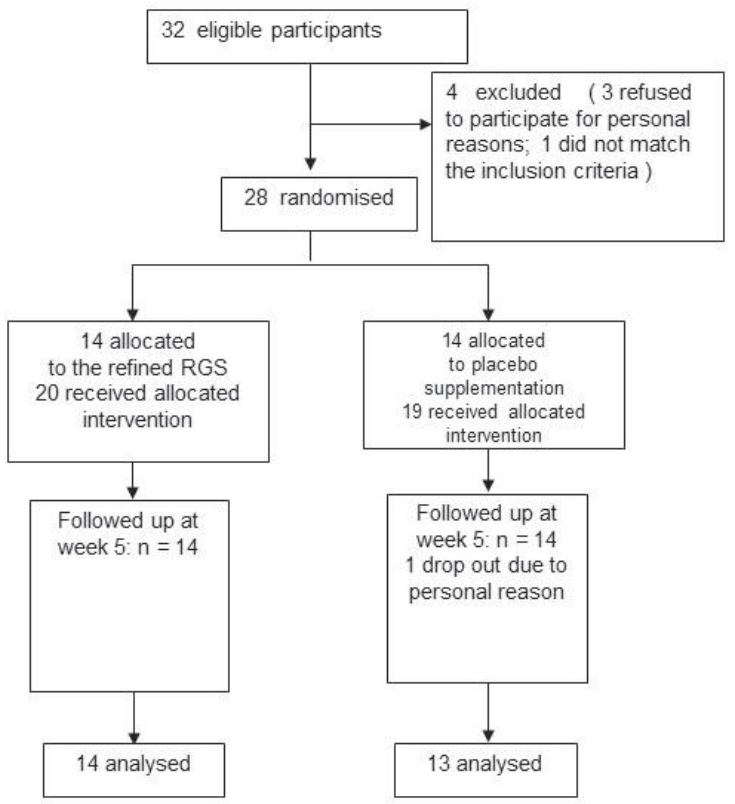

Figure 1. Flow diagram of the study

\section{Adverse events}

Enrolled subjects complained of some adverse events: weariness, psychological stress, headache, nausea, vomiting, laxative effects, insomnia, hypersomnia, drowsiness, noise hypersensitivity, balanced disorders or dizziness,

Table 2. Baseline characteristics of the sample (data are $n$ or mean $\pm S D$ )

\begin{tabular}{lcc}
\hline Variable & Refined $R G(n=14)$ & Placebo $(n=13)$ \\
\hline Demographic variables & & \\
Sex & & 9 \\
$\quad$ Male & 11 & 4 \\
Female & 3 & $30.23 \pm 5.10$ \\
Age (years) & $31.86 \pm 8.06$ & \\
Anthropometric measurements & & $174.50 \pm 9.73$ \\
Height $(\mathrm{cm})$ & $176.70 \pm 8.28$ & $72.32 \pm 12.26$ \\
Weight $(\mathrm{kg})$ & $74.88 \pm 11.35$ & $23.61 \pm 2.31$ \\
Body mass index $\left(\mathrm{kg} / \mathrm{m}^{2}\right)$ & $23.89 \pm 2.67$ & $80.54 \pm 8.41$ \\
Waist circumference $(\mathrm{cm})$ & $82.89 \pm 9.97$ & $96.38 \pm 7.62$ \\
Hip circumference $(\mathrm{cm})$ & $97.71 \pm 5.76$ & $29.19 \pm 3.47$ \\
Mid-arm circumference $(\mathrm{cm})$ & $29.07 \pm 2.63$ & $8.91 \pm 3.83$ \\
Biceps skinfold $(\mathrm{mm})$ & $8.29 \pm 3.36$ & $13.55 \pm 5.38$ \\
Triceps skinfold $(\mathrm{mm})$ & $12.29 \pm 4.81$ & \\
\hline
\end{tabular}

${ }^{*}$ Statistically significant difference $(p<0.05)$ between treatments 


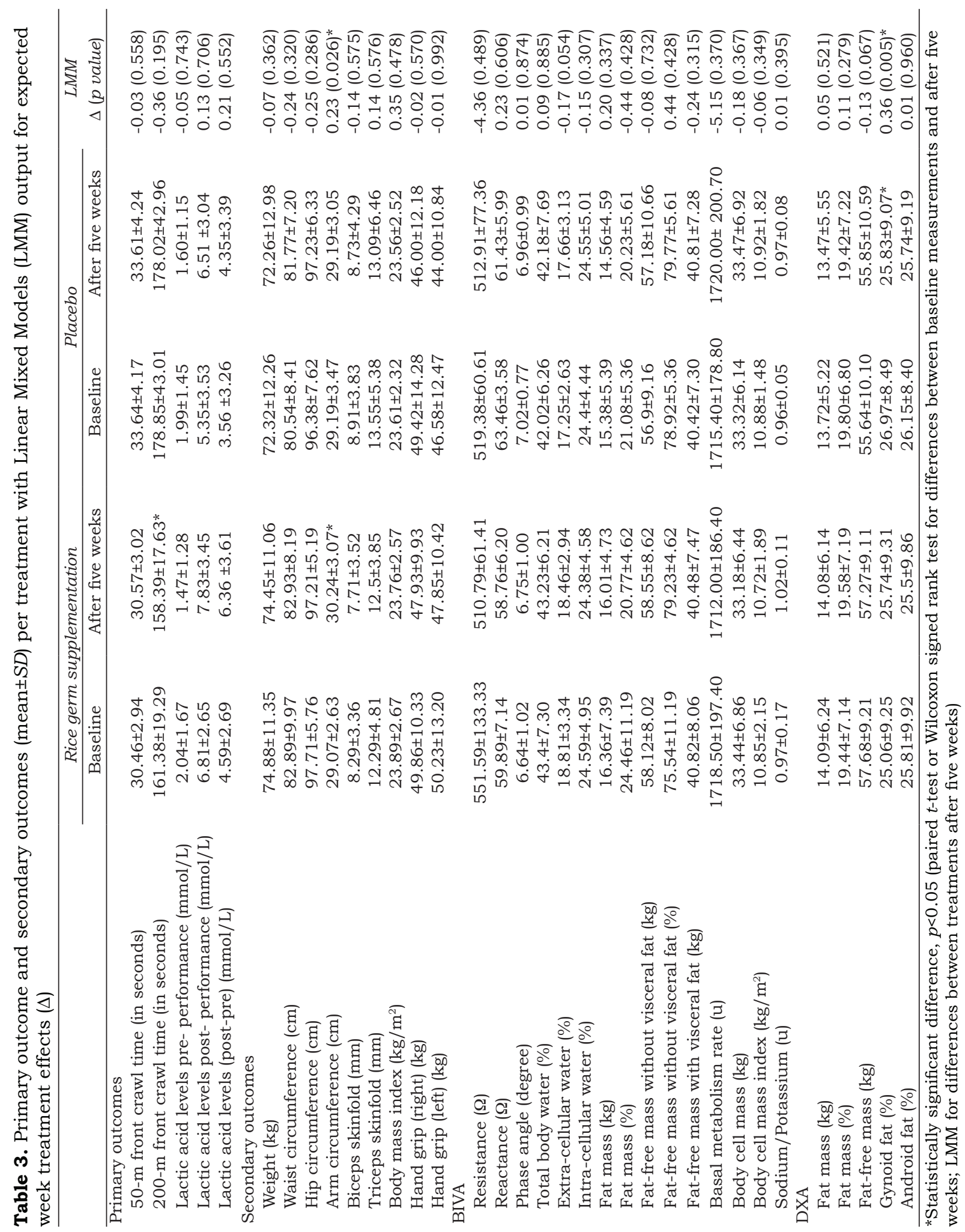


memory disorders, concentration disorders, irritability, sadness, and reduction or increment in training intensity. Concerning headache, it was significantly more frequent in the refined $R G$ supplementation group (mean $\pm S D$ : $2.54 \pm 2.99$ times). Adverse events were not observed at baseline, so we did not assert that headache was a side effect generated by refined RG. However, the headache variable was included in the LMM as a potential confounder because it was related to refined $\mathrm{RG}$.

\section{Primary and secondary outcomes}

Table 3 reports descriptive statistics by arms at baseline and after five weeks of follow-up, as well as the LMM output.

When comparing post-intervention to pre-intervention measurements for each treatment, we observed that the 50-m front crawl time performance remained invariant, while on the $200-\mathrm{m}$, the refined $R G$ supplementation group had a significant average decrease of 2.98 seconds $(p<0.05)$ (Table 3$)$ detected. However, this improvement was not detected by LMM (Table 3, $\Delta=-0.36$, $p>0.05)$ that simultaneously compared the arms across follow-up (adjusted for headache indicator).

Regarding lactic acid markers, we also noticed from Table 3 that the average pre-performance level recorded a slight decrease of $0.05 \mathrm{mmol} / \mathrm{L}$ but it was not significant ( $p>0.05)$. Instead, we revealed non-significant increases in the average post-performance level and average $\Delta$-change of 0.13 and 0.21 $\mathrm{mmol} / \mathrm{L}$, respectively.

Regarding secondary outcomes, there were some interesting evidences for body arms. LMM in Table 3 shows that mean arm circumference was increased by $0.23 \mathrm{~cm}(p<0.05)$, even though biceps skinfold showed a decrease of $0.14 \mathrm{~mm}$, non-significantly $\quad(p>0.05)$ Notably, Table 3 also highlights a significant decrease in mean weight of $0.43 \mathrm{~kg}$ in the refined RG supplementation group, but this significance vanished in LMM ( $\Delta=-0.07, p>0.05)$ when treatment was compared with placebo across follow-up.

Concerning BIVA markers, we pointed out a weak evidence on an average decrease of 0.17 percentage units in extra-cellular water $(p>0.05)$ (Table 3). Table 3 also highlighted a significant decrease in average reactance level in the placebo group, even though the difference between treatments were not significant by LMM (Table $3, \Delta=0.23$, $p>0.05)$. Regarding DXA markers, we recorded a significant increase of $0.36 \%$ in gynoid fat $(p<0.05)$, and a weak evidence of an average decrease of 0.13 $\mathrm{kg}$ in FFM $(p>0.05)$. All other secondary outcomes did not provide any significant findings.

\section{DISCUSSION}

This pilot study was the first study in literature that provided early evidence that a five-week RG supplementation in a group of moderately trained swimmers may positively affect their nutritional status and partially, their performances compared with placebo.

The main result of this study was a significant average decrease of 2.98 seconds on a 200-m front crawl at maximalspeed in the group supplemented with RG, even if it was not significant compared with placebo treatment. This improvement in performance can be considered meaningful for a moderately trained swimmer, as it equals to a reduction of $1.8 \%$ in performance time from baseline. The precise manner by which dietary RG supplementation can affect aerobic efficiency at sub-maximal workload remains unclear, but we have postulated several mechanisms to explain this phenomenon.

First of all, the nutritional composition of RG. A recent study (Rondanelli et al., 2019) demonstrated that RG has 
a high protein content $(18 \mathrm{~g} / 100 \mathrm{~g}$ of edible product, with a good content of essential amino acids: lysine, histidine and valine), a good lipid content (with mono-unsaturated and polyunsaturated fatty acids - in particular linoleic and linolenic essential fatty acids and oleic acid), and a good fibre content $(7 \mathrm{~g} / 100 \mathrm{~g})$. Besides, the most notable water-soluble vitamins in it are thiamine (B1) and pyridoxine (B6), while vitamin E prevails for liposoluble vitamins. Specifically, an intake of $100 \mathrm{~g}$ RG can meet the average needs of RDAs for the general population (483\% for B1, $212 \%$ for vitamin E). It also contains quantitative discrete amounts of vitamin B6 (pyridoxine). Minerals that are most present are iron $177 \%$ of RDA) and magnesium (108\% of RDA). As reported in the introduction, all these nutrients have a pivotal role in muscle functioning, therefore can influence sports performance.

The timing of supplementation appears to be crucial, especially for protein and amino acids intakes, as arising evidence strongly suggests that quantity, timing and types of protein intake in relation to exercise sessions have a marked effect on the efficacy of protein synthesis, optimising post-exercise recovery and consequently improving sports performance (Stellingwerff et al., 2011). The RG supplementation was taken twice daily: $25 \mathrm{~g}$ in the morning with breakfast and $25 \mathrm{~g}$ in the afternoon as snacks, as suggested by the literature in order to optimise protein synthesis (Naderi et al., 2016), and also to have beneficial effects such as reduced muscle soreness and markers of muscle damage that were more evident when supplemental protein was consumed after daily training sessions (Pasiakos, Lieberman \& McLellan, 2014).

Another significant result concerns the nutritional status of swimmers, whereby there was an increase from baseline in the arm circumference of the
RG group, which was also statistically significant when compared to the placebo group. The BC of athletes is an important determinant of health and performance (Malina \& Geithner, 2011). The reason for this increase can't be completely elucidated, because there were no previous studies on this topic in the literature. In particular, we cannot assess if this increase was due to a variation in FFM or FM. Nevertheless, considering that the RG group experienced a statistically significant improvement in the 200-m performance and an increase in total FFM, though not statistically significant, we assumed that the increase in arm circumference could be due to an increase in arm FFM, which could be related to the high protein content of RG. However, we cannot affirm this with certainty.

Gynoid fat also had a statistically significant increase in the RG supplementation group compared to the placebo group. Unfortunately, literature is lacking in evidence that could explain this finding. No statistically significant intra- or inter-group differences were detected for the other secondary outcomes evaluated. We hypothesise that probably the five weeks of RG supplementation were not enough to detect significant changes in these parameters. However, there are no studies in the literature that allowed us to compare this topic.

\section{Perspective}

Results of the present research may have potential practical applicability as it indicated that RG supplementation may be suitable to enhance exercise performance in swimming. RG supplementation, considered as a concentrated mixture of B-group vitamins, minerals and vegetal proteins, showed itself as an interesting potential nutraceutical for swimmers and other power sports, even if the results of this study were limited and other 
confirmations are needed. In particular, the number of subjects studied and the time taken for the dietary supplement must be increased.

\section{Study limitations}

The main limitation of this study was not evaluating certain physiological parameters, such as oxygen uptake $\left(\mathrm{VO}_{2}\right)$ and anaerobic threshold (AT), that would have been useful in understanding the mechanisms of action of RG on performance. However, these parameters were hampered by technical limitations during swimming due to difficulty of assessment of expired gases in a pool.

In addition, despite a non-significance difference in mean performance of the 200-m front crawl time between the two groups, a difference of almost 20 seconds between these two groups could have an impact on the interpretation of the results. Concerning that, nonsignificant results might have been due to the sample size, therefore future studies might take into account larger samples.

\section{CONCLUSION}

In conclusion, the RG dietary supplement met all the requirements that a dietary supplement must possess to be suitable for supplementation in athletes, according to the International Olympic Committee (IOC) consensus statement (Maughan et al., 2018): 1. The management of micronutrient deficiencies (in particular, iron), 2. Supply of convenient forms of energy and macronutrients (in particular proteins), as demonstrated by the increase of arm circumference in the RG group from baseline, and 3. Provision of direct benefits to performance, as demonstrated by the significant decrease of 2.98 seconds on a 200-m front crawl at maximal speed.

\section{Acknowledgements}

This study was supported by the University of Pavia, the Italian Ministry of Scientific Research, and the Federazione Italiana Nuoto (FIN) of Italy. The results of the current study do not constitute endorsement of the product by the authors or the journal.

\section{Authors' contributions}

MR and SP, principal investigators, conceptualised and designed the study, prepared the draft of the manuscript and reviewed the manuscript; DS, GP, VI, MAF and MN, led the data collection, advised on data analysis and interpretation and reviewed the manuscript; GI and CG, reviewed the manuscript; DG, conducted data analysis and interpretation, prepared the draft and reviewed the manuscript.

\section{Conflict of interest}

None to declare.

\section{References}

ACSM, ADA \& Dietitians of Canada (2000). Joint Position Statement: nutrition and athletic performance. American College of Sports Medicine, American Dietetic Association, and Dietitians of Canada. Med Sci Sport Exer 32(12):2130-2145. http://www.ncbi.nlm.nih. gov/pubmed/11128862

Camina Martín MA, de Mateo Silleras B, Carreño Enciso L, de la Cruz Marcos S, Miján de la Torre A \& Redondo del Río MP (2013). Changes in body composition in relation to the stage of dementia in a group of institutionalized elderly. Nutr Hosp 28(4):1093-1101. https:// doi.org/10.3305/nh.2013.28.4.6403

De Carvalho FG, Barbieri RA, Carvalho MB, Dato CC, Campos EZ, Gobbi RB, Papoti M, Silva ASR \& de Freitas EC (2018). Taurine supplementation can increase lipolysis and affect the contribution of energy systems during front crawl maximal effort. Amino Acids 50(1):189-198. s00726-017-2505-3

European Medicines Agency (2010). Guideline on missing data in confirmatory clinical trials. Committee for Medicinal Products for Human Use (CHMP), European Medicines Agency. http://en.cnki.com.cn/Article_en/CJFDTotalZXYZ201207010.htm

Fitzmaurice GM, Laird NM \& Ware JH (2011). Applied longitudinal analysis. Wiley. 
Fouré A \& Bendahan D (2017). Is branched-chain amino acids supplementation an efficient nutritional strategy to alleviate skeletal muscle damage? A systematic review. Nutrients 9(10). https://doi.org/ 10.3390/nu9101047

Fox J (2005). The R commander: A basic-statistics graphical user interface to R. J Stat Softw 014(i09):1-42. https://econpapers.repec.org/ article/jssjstsof/v_3a014_3ai09.htm

Frisancho AR (1984). New standards of weight and body composition by frame size and height for assessment of nutritional status of adults and the elderly. Am J Clin Nutr 40(4):808-819. https://doi.org/ 10.1093/ajcn/40.4.808

Gao J, Costill DL, Horswill CA \& Park SH (1988). Sodium bicarbonate ingestion improves performance in interval swimming. Eur $J$ Appl Physiol Occup Physiol 58(1-2):171-174. https:/ / doi.org/ 10.1007/BF00636622

Iverson GL, Lovell MR \& Collins MW (2003). Interpreting change on ImPACT following sport concussion. Clin Neuropsychol 17(4), 460-467. https: / /doi.org/ 10.1076/clin.17.4.460.27934

Julious SA (2005). Sample size of 12 per group rule of thumb for a pilot study. Pharm Stat. https: / / doi.org/10.1002/pst. 185

Knapik JJ, Steelman RA, Hoedebecke SS, Austin KG, Farina EK \& Lieberman HR (2016). Prevalence of dietary supplement use by athletes: systematic review and meta-analysis. Sports Med 46(1):103-123. https://doi. org/10.1007/s40279-015-0387-7

Kyle UG, Genton L, Karsegard L, Slosman DO \& Pichard C (2001). Single prediction equation for bioelectrical impedance analysis in adults aged 20-94 years. Nutrition 17(3):248-253. https:// doi.org/10.1016/S0899-9007(00)00553-0

Lindh A, Peyrebrune M, Ingham S, Bailey D $\&$ Folland J (2008). Sodium bicarbonate improves swimming performance. Int $J$ Sports Med 29(6):519-523. https://doi. org/10.1055/s-2007-989228

Lohman TG, Roche AF, Kinetics RM-UCIH (1991). Anthropometric standarization reference manual. Sidalc.Net. From http://www.sidalc. net/cgi-bin/wxis.exe/ ? Isis Script=BINCAP. xis $\&$ method $=$ post $\&$ for $m a t o=2 \&$ cantidad $=$ 1 \&expresion $=\mathrm{mfn}=000920$

[Retrieved December 5 2018]

Lowings S, Shannon OM, Deighton K, Matu J \& Barlow MJ (2017). Effect of dietary nitrate supplementation on swimming performance in trained swimmers. Int $J$ Sport Nutr Exerc Metab 27(4):377-384. https://doi.org/10.1123/ ijsnem.2016-0251
Maharam LG, Bauman PA, Kalman D, Skolnik H \& Perle SM (1999). Masters athletes. Factors affecting performance. In Sports Med 28(4):273285. https://doi.org/10.2165/00007256199928040-00005

Malina RM \& Geithner CA (2011) Body composition of young athletes. Am J Lifestyle Med 5(3):262-278. https://doi. org/ $10.1177 / 1559827610392493$

Manore M, Meyer NL \& Thompson J (2009). Sport nutrition for health and performance. Human Kinetics. From https:// books.google.it/books?hl $=\mathrm{it} \& 1 \mathrm{r}=\& \mathrm{id}=\mathrm{UAWJVHHTM} 2 \mathrm{QC} \& \mathrm{oi}=\mathrm{fnd} \& \mathrm{pg}=$ PR15\&dq=Sport+nutrition+for+health+and+ performance\&ots $=7$ KYoaxtbHD\&sig= fjV4bnYOXslbbIW9 19 iknOra9bc\#v= onepage\&q=Sport nutrition for health and performance\&f=false [Retrieved June 25 2020]

Maughan RJ, Burke LM, Dvorak J, Larson-Meyer DE, Peeling P, Phillips SM, Rawson ES, Walsh NP, Garthe I, Geyer H, Meeusen R, Van Loon LJC, Shirreffs SM, Spriet LL, Stuart M, Vernec A, Currell K, Ali VM, Budgett RG... Engebretsen L (2018). IOC consensus statement: Dietary supplements and the high-performance athlete. Br J Sports Med 52(7):439-455. BMJ Publishing Group. https://doi.org/10.1136/ bjsports-2018-099027

Maughan RJ \& Shirreffs SM (2015) Exercise and sports. World Rev Nutr Diet 111:71-75. https:/ / doi.org/10.1159/000362301

Mero AA, Hirvonen P, Saarela J, Hulmi JJ, Hoffman JR \& Stout JR (2013). Effect of sodium bicarbonate and beta-alanine supplementation on maximal sprint swimming. J Int Soc Sport Nutr 10(1):52. https://doi.org/10.1186/15502783-10-52

Naderi A, de Oliveira EP, Ziegenfuss TN \& Willems MET (2016). Timing, optimal dose and intake duration of dietary supplements with evidence-based use in sports nutrition. J Exerc Nutrition Biochem 20(4):1-12. https://doi. org/10.20463/jenb.2016.0031

Pasiakos SM, Lieberman HR \& McLellan TM (2014). Effects of protein supplements on muscle damage, soreness and recovery of muscle function and physical performance: A systematic review. Sports Med 44(5):655-670. https:/ / doi.org/10.1007/s40279-013-0137-7

Perretti G, Miniati E, Montanari L \& Fantozzi P (2003). Improving the value of rice by-products by SFE. J Supercrit Fluid 26(1):63-71. https:/ / doi.org/10.1016/S0896-8446(02)00247-4 
Piccoli A, Nigrelli S, Caberlotto A, Bottazzo S \& Rossi B (1995). Bivariate normal values of the bioelectrical impedance vector in adult and elderly populations. Arn J Clin Nutr 61.

Pinheiro J, Bates D, DebRoy S \& Sarkar D (2007). nlme: Linear and Nonlinear Mixed Effects Models. R package version 3.1-108 From: https://cran.r-project.org/web/packages / nlme/nlme.pdf [Retrieved June 22]

Potgieter S (2013). Sport nutrition: A review of the latest guidelines for exercise and sport nutrition from the American College of Sport Nutrition, the International Olympic Committee and the International Society for Sports Nutrition. South Afr J Clin Nutr 26(1): 6-16. https://doi. org/ 10.1080/16070658.2013.11734434

Prosser J, Majlesi N, Chan G, Olsen D, Hoffman R \& Nelson L (2009). Adverse effects associated with arginine a-ketoglutarate containing supplements. Hum Exp Toxicol 28(5):259-262. https://doi.org/10.1177/0960327109104498

Rodriguez NR, DiMarco NM, Langley S (2009). Position of the American Dietetic Association, Dietitians of Canada, and the American College of Sports Medicine: Nutrition and athletic performance. J Am Diet Assoc 109(3):509-527. https://doi.org/10.1016/J.JADA.2009.01.005

Rondanelli M, Miccono A, Peroni G, Nichetti M, Infantino V, Spadaccini D, Alalwan TA, Faliva MA \& Perna S (2019). Rice germ macro- and micronutrients: a new opportunity for the nutraceutics. Nat Prod Res. https://doi.org/1 0.1080/14786419.2019.1660329

Russell C, Papadopoulos E, Mezil Y, Wells GD, Plyley MJ, Greenway M \& Klentrou P (2014). Acute versus chronic supplementation of sodium citrate on $200 \mathrm{~m}$ performance in adolescent swimmers. $J$ Int Soc Sport Nutr 11(1):26. https://doi.org/10.1186/15502783-11-26

Sarkar D (2008). Lattice: multivariate data visualization with $R$. Springer, New York. ISBN 978-0-387-75968-5

Schutz Y, Kyle U \& Pichard C (2002). Fat-free mass index and fat mass index percentiles in Caucasians aged 18-98 y. Int J Obes 26(7):953960. https://doi.org/10.1038/sj.ijo.0802037
Siegler JC, Marshall PWM, Bray J \& Towlson C (2012). Sodium bicarbonate supplementation and ingestion timing. $J$ Strength Cond Res 26(7):1953-1958. https://doi.org/10.1519/ JSC.0b013e3182392960

Siegler JC, Midgley AW, Polman RCJ \& Lever R (2010). Effects of various sodium bicarbonate loading protocols on the time-dependent extracellular buffering profile. $J$ Strength Cond Res 24(9):2551-2557. https://doi. org/10.1519/JSC.0b013e3181aeb154

Spijkerman, Dorine C, Snijders, Chris J, Stijnen, Theo \& Lankhorst GJ (1991). Standardisation of grip strength measurements. Effects on repeatability and peak force. Scand $J$ Rehabil Med 23(4):203-206. https://www. researchgate.net/publication/21370834

Stellingwerff T, Maughan RJ \& Burke LM (2011). Nutrition for power sports: Middle-distance running, track cycling, rowing, canoeing/ kayaking, and swimming. $J$ Sports Sci 29(sup1):S79-S89. https://doi.org/10.1080/0 2640414.2011.589469

Tang FC (2006). Influence of branched-chain amino acid supplementation on urinary protein metabolite concentrations after swimming. $J$ Am Coll Nutr 25(3):188-194. https://doi.org/ 1 0.1080/07315724.2006.10719531

Tantrum M \& Hodge K (1993). Motives for participating in masters swimming. New Zealand Journal of Health, Physical Education \& Recreation 26:3-7. ISSN: 0028-8314. From https://www.cabdirect.org/cabdirect/ abstract/19931857066 [Retrieved June 25 2020]

Team R (2013). R: A language and environment for statistical computing.

Toussaint HM \& Hollander AP (1994). Energetics of competitive swimming: implications for training programmes. Sports Med 18(6): 384-405. https: / / doi.org/10.2165/00007256199418060-00004 